\title{
Promoting access to treatment for patients with haemoglobin disorders
}

\author{
L. Perickleous
}

\begin{abstract}
For the thalassaemia syndromes the Thalassaemia International Federation, the international patients' organization has been struggling since its inception in 1987 to facilitate access to treatment for all thalassaemia patients across the globe. Ever since we accepted the doctrine that where strong patient organisation exists, we have observed that there has been a marked improvement in the health care services provided for the haemoglobin disorders worldwide. Unfortunately personality or ego issues and lack or inexperience of strategic planning have always proved to be major drawbacks in achieving collective goals for patients. But the biggest obstacle to access to treatment in the years of my early adulthood has been no other than my self. Having finally secured safe and adequate blood, sample chelating agents and excellent medical professionals, I had decided that I had enough and I stopped chelating. I know now that the access to treatment has as much to do with our determination to live and prosper as with the influence of our countrymen to provide to the less privileged. My disorder provided me with much more than I could ever pray for... Thank God.
\end{abstract}

\section{Issue 1}

Back in 2001, Sir David Weatherall and his colleague J.B. Clegg, published an all time classic article for the World Health Organization with the title Inherited haemoglobin disorders: an increasing global health problem.

Their findings are well described in their abstract:

Despite major advances in our understanding of the molecular pathology, pathophysiology, and control and management of the inherited disorders of haemoglobin, thousands of infants and children with these diseases are dying through lack of appropriate medical care. This problem will undoubtedly increase over the next 20 years because, as the result of a reduction in childhood mortality due to infection and

(C) Copyright L. Perickleous, 2011

Licensee PAGEPress, Italy

Thalassemia Reports 2011; 1(s2):e2

doi:10.4081/thal.2011.s2.e2

This article is distributed under the terms of the Creative Commons Attribution Noncommercial License (by-nc 3.0) which permits any noncommercial use, distribution, and reproduction in any medium, provided the original author(s) and source are credited.

Parts of this work were presented at the "12th International Conference on Thalassemia and Hemoglobinopathies", Antalya (Turkey), 11-14 May 2011. malnutrition, more babies with haemoglobin disorders will survive to present for treatment. Although $\mathrm{WHO}$ and various voluntary agencies have tried to disseminate information about these diseases, they are rarely mentioned as being sufficiently important to be included in setting health care priorities for the future. It takes considerable time to establish expertise in developing programmes for the control and management of these conditions, and the lessons learned in developed countries will need to be transmitted to those countries in which they occur at a high frequency.

The tragic statement ten years later is still very much valid and thousands of infants and children with haemoglobin disorders are dying through lack of treatment. What makes it even more tragic nowadays is the knowledge that patients with appropriate medical care can lead near normal lives and live to old age.

\section{Issue 2}

For the thalassaemia syndromes the Thalassaemia International Federation, the international patients' organization has been struggling since its inception in 1987 to facilitate access to treatment for all thalassaemia patients across the globe. The Federation has consistently in its wisdom followed a specific model, which is pragmatic and effective where it has been allowed to be implemented.

Prevention programs have always been considered as a prerequisite for having a basic standard of treatment in any given region or country. If the number of patients is allowed to increase without the implementation of any preventive measures then the patients alive are less likely to get proper treatment due to limited resources; concurrently, transfusion dependent patients will definitely not be able to get adequate transfusion levels since blood is scarce, and in order for blood to be safe and of good quality, it needs to be voluntarily donated and not purchased in the open market. For prevention, we are absolutely not advocating for abortion.

On the contrary, the international Federation is promoting screening programs in order for prospective parents to be informed of their condition, and therefore take an informed decision based on their culture, religion, ethics, social and personal convictions.

\section{Issue 3}

Let me take the example of my country, Cyprus, where the pre-marital certificate was introduced by the Christian Orthodox Church of Cyprus in an effort to contain the birth of new thalassaemics since the country could not support its thalassaemic population in terms of blood and medical care. Since the introduction of the pre-marital screening in the late seventies and the minimization of new births, the standard of care dramatically improved with the free provision of chelating agents and the availability of adequate and safe blood. 


\section{Issue 4}

However, the primary pre-condition for a good standard of care and treatment is the existence of a united and strong patient voice to present and claim from the health authorities the right to life.

The creation of an organization of parents and patients has been instrumental in facilitating access to health care resources in order to preserve or improve patients' health.

Pioneering patients' organizations in the US, Cyprus, UK, Italy and Greece in the 1960 s had initially managed to get the attention of medical doctors and scientists in the haemoglobin disorders and consequently the attention of the health authorities in their respective countries. In very few cases worldwide, individually inspired health professionals promoted the creation or empowerment of the patient organizations in an effort to further promote the health care of their patients. The creation of the Thalassaemia International Federation in the 1980 s spearheaded the creation of parents and patients organizations in all the countries or regions where haemoglobinopathies were prevalent, but treatment had been either non-existent or sub-optimal.

\section{Issue 5}

Ever since we accepted the doctrine that where strong patient organisation exists, we have observed that there has been a marked improvement in the health care services provided for the haemoglobin disorders in the given region.

\section{Issue 6}

Unfortunately personality or ego issues and lack or inexperience of strategic planning have always proved to be major drawbacks in achieving collective goals for patients.

\section{Issue 7}

We are of the opinion that our motto Unity is our strength describes exactly what is needed for a patients organization to be effective. As a forty five year old person with transfusion-dependent thalassaemia, I am able to state that my life line coincides with the different phases we have or still face as patients with haemoglobin disorder. At the early years of my life there was minimal treatment, and access to health care had been difficult and problematic if at all possible. There were no chelating agents freely available and getting a unit of blood had been an adventure for our parents to say the least. That was the time that distinguished medical professionals were saying to our parents that there is no life or future for us. But God gave people the greatest gift of hope. Few determined parents had decided against the opinion of the medical profession and started fighting for their children. From that moment onward things gradually got better as those parents were organized into an association and started demanding a treatment for their offsprings. They had managed in few years to get the chelating agent provided free of charge. They had also organized a voluntary blood collection service to secure adequate and safe blood for the patients.

At about the same time few young medical professionals were sensitised by this collective activity, and they started to show an extreme interest on these patients, that only a few years before were left to die in slow and agonizing deaths. It seems that hope is contagious and those professionals were infected with that hope and started working and substantially improving the health care of patients with haemoglobin disorders. But the biggest obstacle to access to treatment in the years of my early adulthood has been no other than my self. Having finally secured safe and adequate blood, sample chelating agents and excellent medical professionals, I had decided that I had enough and I stopped chelating. The consequences were not immediate but unavoidable; insulin dependent diabetes and deterioration of the heart function transpired. It seems that the prayers of my loved ones were heard as I escaped the inevitable and changed my mind on time. However, not everyone has had my lucky star, and we have lost a great number of dear friends due to our greatest enemy, ourselves.

At this stage of supposed maturity I face the future with hope and a touch of fear as any other human being on the planet. I know now that the access to treatment has as much to do with our determination to live and prosper as with the influence of our countrymen to provide to the less privileged. My disorder provided me with much more than I could ever pray for... Thank God. 